\title{
Seasonal variability in fungal endophytes from Aizoaceae plants in the Succulent Karoo biodiversity hotspot, South Africa
}

Zelda Pieterse $^{1}$, Theresa A. S. Aveling ${ }^{1}$, Adriaana Jacobs ${ }^{2}$, Don A. Cowan ${ }^{3}$.

${ }^{1}$ Department of Plant and Soil Sciences, Forestry and Agriculture Biotechnology Institute, University of Pretoria, Pretoria, 0001, South Africa.

${ }^{2}$ Plant Health and Protection - Biosystematics, Agriculture Research Council, Pretoria, 0001, South Africa.

${ }^{3}$ Centre for Microbial Ecology and Genomics, Department of Genetics, University of Pretoria, Pretoria 0001, South Africa.

Corresponding author: Prof Theresa A. S. Aveling

Telephone number: 27124205153

E-mail address: terry.aveling@up.ac.za 


\begin{abstract}
All ten species of Aizoaceae screened in this study were populated with endophytes. Fifty nine fungal species from 25 genera, including fourteen rare species, were identified. Seasonal specificity was observed; with 32 and 21 fungal endophytes isolated only during the flowering and dry seasons, respectively. The genus Fusarium was the most abundant in samples from the flowering season, whilst Alternaria and Cladosporium were equally abundant in the dry season. Rarely isolated genera included Neophaeosphaeria, Periconia, Preussia, Schizothecium and Truncatella. Fusarium oxysporum, Paecilomyces victoriae and Talaromyces pinophilus were the largest contributors to the differences in community structure observed for fungal endophytes from the different seasons. Endophytic fungal richness was very high in comparison to other global arid regions. This is the first record of all these fungal species isolated from Aizoaceae plants in their endemic environment in the most biodiverse arid region in the world, the Succulent Karoo in South Africa.
\end{abstract}

\title{
KEYWORDS
}

Conservation; fungal diversity; mesembs; Namaqua National Park; rare species; seasonality 


\section{Introduction}

Since the official establishment of Biodiversity Hotspots in 1989, the International Union for Conservation (IUCN) has recognised the Succulent Karoo in South Africa as the most biodiverse arid region in the world due to its incomparable alpha (local) diversity, astonishing beta diversity along habitat gradients and gamma diversity along geographical gradients (Myers, 2000; Desmet and Cowling, 2004; Sloan et al., 2014). In spite of its ecological and socioeconomic importance the natural habitat of the Succulent Karoo has been subjected to intense destruction and little has been done to protect its natural resources (SANParks, 2014). Within this ecoregion a family of leaf succulents, the Aizoaceae (Caryophyllales, Plantae) represent the most remarkable radiation in the entire plant kingdom, with a single ancestor diverging into numerous species (Klak et al., 2004). Commonly known as mesembs or "ice plants", or by their Afrikaans vernacular name of "vygies" in South Africa, these endemic plants thrive despite nutrient poor soils, limited water availability and large diurnal temperature fluctuations (Smith et al., 1998).

Recent studies have highlighted the importance of the contribution of microbial life to plant thermotolerance, drought resistance and other important survival strategies by showing that diverse secondary metabolites are produced by the endophytic fungi harboured inside the plants rather than by the plants themselves (Moncrieff et al., 2015; Mishra et al., 2016). Fungal endophytes are phylogenetically diverse microscopic, eukaryotic organisms that colonise, either inter- or intra-cellularly, the healthy living, internal tissues of their host without causing any disease symptoms (Rodriguez et al., 2009; Massimo et al., 2015). Most studies exploring endophytes have been done in humid regions, with surprisingly few studies done in arid and semi-arid regions, where the focus has only been on cacti or grass species (Suryanarayanan et al., 2005; Loro et al., 2012; Bezerra et al., 2012, 2013). 
Seasonality has been shown to influence fungal endophytic communities associated with olive trees in the Mediterranean (Martins et al., 2016) as well as black plum in India (Yadav et al., 2016) while in other regions such as the Atlantic rain forest seasonality has been shown to be of minor importance (Bonfim et al., 2016). In the Namaqua National Park, sited in the South African Succulent Karoo biodiversity hotspot, the dynamics of plant communities change dramatically after the rainfall period, from May to September, when more than $60 \%$ of the annual precipitation occurs (South African Weather Service, www.weathersa.co.za).

This study is founded on the hypothesis that the fungal endophyte diversity associated with mesembs in the Succulent Karoo will be high and influenced by seasonality. The objectives of this study were: 1) to isolate and identify fungal endophytes from Aizoaceae species in the Namaqua National Park during the dry and flowering seasons; 2) to determine the influence of seasonality on community composition and 3) to explore fungal species richness and diversity in comparison with similar studies from other dry environments.

\section{Materials and methods}

\subsection{Study site and sampling}

Sampling occurred before and after the highest rainfall period (June-August) in the Succulent Karoo, Northern Cape Province, South Africa. In September 2013, during the flowering season Aizoaceae plants were collected from three selected sampling locations near the Skilpad camp (3009'19’'S; $17^{\circ} 43^{\prime} 55^{\prime \prime}$ ), in Namaqua National Park, a protected area inside the Succulent Karoo biodiversity hotspot (Fig. 1). Plots were $20 \mathrm{~m}^{2}$ in size, divided into 10 blocks in three rows. Aizoaceae plants were also collected from the same three sampling locations during the flowering season (September-October) of 2014. 


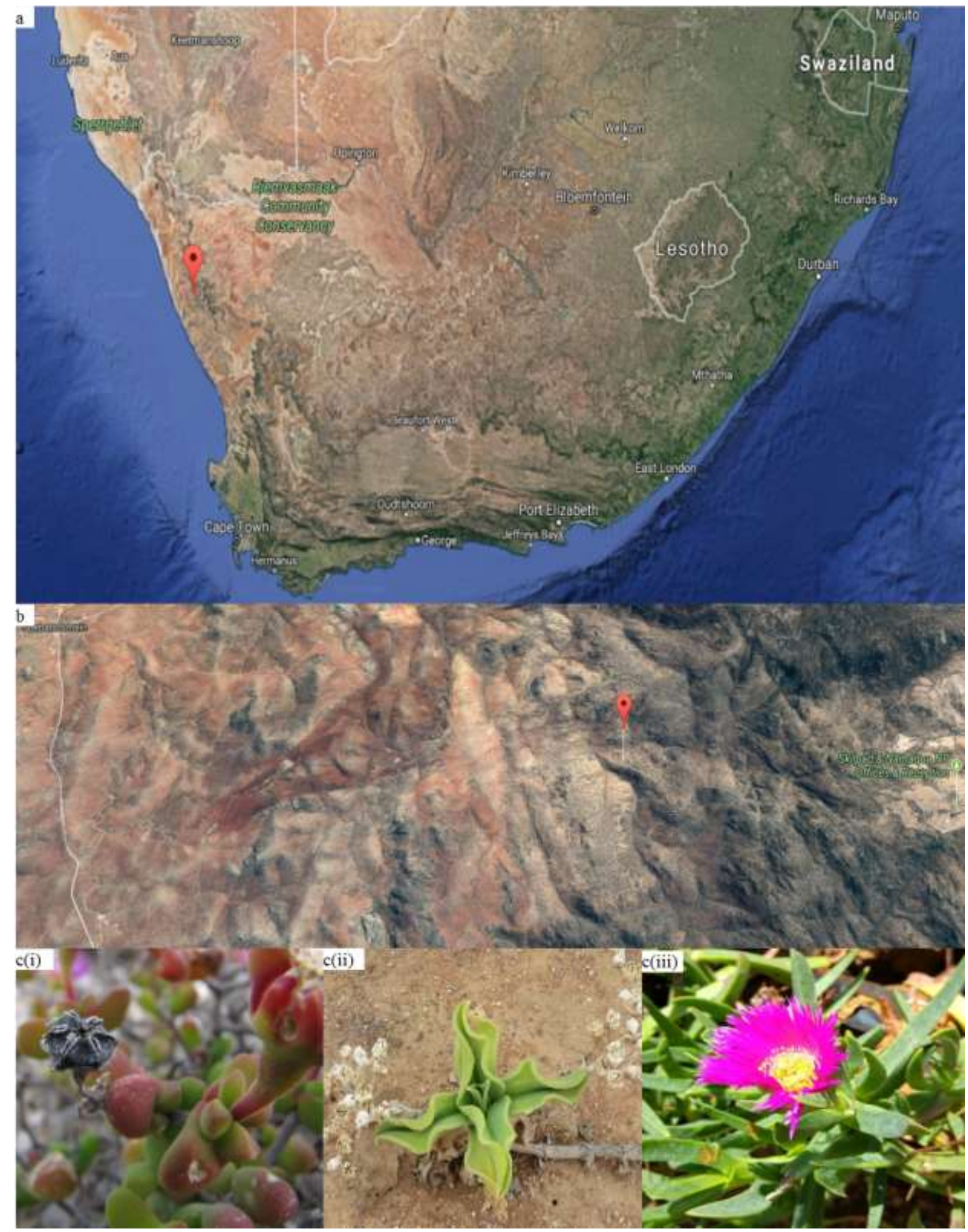

Fig. 1.a) Map of South Africa indicating the sampling site; b Map of the sampling site, close to Skilpad camp in the Namaqua National Park, in the Succulent Karoo biome in South Africa

(Google maps, 2017); c) three species of mesemb plants, (i) Drosanthemum diversifolium, (ii)

Mesembryanthemum barklyi, (iii) Carpobrotus edulis. 
These sites were also re-sampled at the end of the dry season, in May of 2014 and 2015. As this area is a South African National Park, a permit to conduct this study was obtained from South African National Parks (SANParks: permit number CRC/2015/010--2014). No endangered species were sampled or disturbed during the sampling process. Common Aizoaceae plants were removed from each site on each of four collecting trips, for a total of 45 plants. Plant material was transported in brown paper bags at temperatures below $10^{\circ} \mathrm{C}$ in a cooler box, then refrigerated at $4^{\circ} \mathrm{C}$ and processing took place within $96 \mathrm{~h}$ of collection. All samples collected during all sampling trips were treated in the same manner to minimize the possible influence of fungal opportunists that might have intruded during transportation.

\subsection{Endophyte isolation}

Aerial plant tissues were surface sterilized by immersion in $70 \%$ ethanol $(\mathrm{EtOH})$ for $1 \mathrm{~min}$, followed by $1 \%$ aqueous sodium hypochlorite $(\mathrm{NaClO})$ solution for $3 \mathrm{~min}$ and $75 \%$ ethanol for $1 \mathrm{~min}$ to remove epiphyllous fungi and contaminants. Samples were rinsed three times with double distilled (dd) $\mathrm{H}_{2} \mathrm{O}$ and dried under sterile conditions inside a laminar flow cabinet. Small fragments $(5-10 \mathrm{~mm})$ of leaf material were aseptically removed from each plant with forceps and plated onto potato dextrose agar (PDA) (Biolab, Merck, Darmstadt, Germany) in 90mm Petri dishes. Plates were sealed with Parafilm $^{\circledR}$ and incubated at 10,20 and $30^{\circ} \mathrm{C}$, under $12 \mathrm{~h}$ day/night light regime for a maximum period of six weeks. Plates were evaluated every $48 \mathrm{~h}$ and hyphae from emerging fungal colonies were selected and transferred to fresh PDA in 45mm Petri dishes for purification and further morphological identification. All representative isolates were deposited into the South African National Collection of Fungi living fungal collection (PPRI), where cultures are maintained. 


\subsection{Endophyte identification}

Fungal identity was determined by colony morphology and microscopic morphological characters and distinct isolates were subjected to further molecular identification. DNA was extracted from fungal mycelia using the DNAeasy® Plant Mini Kit (Qiagen, Valencia, CA, USA) according to the manufacturer's specifications. Extracted DNA was used as a template to PCR amplify the ITS region using the primer set ITS 1 and ITS 4 (White et al., 1990), performed in a total reaction volume of $25 \mu \mathrm{l}$, which included $2 \mu \mathrm{l}$ of 10x DreamTaq DNA buffer (Thermo Fisher Scientific, Waltham, MA), $2 \mu 1$ of $25 \mu \mathrm{M}$ dNTPs (Promega Corp., Madison, WI), $0.5 \mu 1(0.2 \mu \mathrm{M})$ of each primer (Sigma-Aldrich, St. Louis), $0.2 \mu \mathrm{l}(5 \mathrm{U} / \mu \mathrm{l})$ DreamTaq DNA polymerase (Thermo Fisher Scientific, Waltham, MA), $2 \mu$ l template DNA and $\mathrm{ddH}_{2} \mathrm{O}$ to a total volume of $25 \mu \mathrm{l}$. The PCR reaction conditions were an initial denaturation step at $94^{\circ} \mathrm{C}$ for $2 \mathrm{~min}$, followed by 30 cycles of denaturation at $94^{\circ} \mathrm{C}$ for $30 \mathrm{~s}$, annealing at $52^{\circ} \mathrm{C}$ for 30 s and elongation at $72^{\circ} \mathrm{C}$ for $45 \mathrm{~s}$, with a final elongation step of $72^{\circ} \mathrm{C}$ for $7 \mathrm{~min}$. PCR products were visualized on $1 \%$ agarose gels at $80 \mathrm{~V}$ for $30 \mathrm{~min}$ and stained with ethidium bromide at a concentration of $1 \mu \mathrm{g} / \mu \mathrm{l}$. DNA sequences from PCR amplicons were determined using the ABI PRISM Dye Terminator Cycle Sequencing Ready Reaction Kit with AmpliTaq ${ }^{\circledR}$ DNA Polymerase (Applied Biosystems, Paisley, UK) using both forward and reverse primers for each gene region. Consensus sequences were manually edited (where necessary) in BioEdit version 7.2.5. (Hall, 1999) and compared to those published on NCBI's GenBank sequence database (http://www.ncbi.nlm.nih.gov) as well as MycoBank (www.mycobank.org) (Crous et al., 2004) by means of BLASTn analyses. If the similarity based on the ITS region was $>97 \%$, the most similar reference sequence from these databases was used to assign identity. An identical name was assigned to sequences sharing less than $5 \%$ nucleotide difference. The global fungal nomenclature database www.indexfungorum.org was used to ensure that the most current name of fungal species was used and to eliminate synonymy. 


\subsection{Biodiversity measurements}

The relative abundance of endophytic fungi was calculated by dividing the number of isolates of each species by the total number of isolates and multiplying by 100 (Table 1). Colonization frequency was calculated by dividing the number of colonized segments into the total number of segments incubated and reported as a percentage. Species diversity was estimated by various indices (Table 2) using PAST 3.14 (Hammer et al., 2001) with a bootstrap value of 9999 and a 95\% confidence interval. The species accumulation curve was constructed by implementing the analytical solution known as "Mao's tau", with standard deviation and standard error converted to 95\% confidence intervals. Analysis of similarity (ANOSIM) was used to determine differences in relative abundance of fungal endophytes (Clarke, 1993). Differences in fungal endophyte communities isolated from Aizoaceae in the dry and flowering season were visualised by nonmetric multidimensional scaling (NMDS) ordination using the Bray-Curtis dissimilarity index for relative abundance data as well as the Jaccard dissimilarity index for binary (presence / absence) data (Taguchi and Oono, 2005). A similarity percentages analysis (SIMPER) was used to investigate whether certain species were chiefly responsible for differences observed with NMDS analysis (Clarke, 1993).

\section{Results}

All mesemb species (Mesembryanthemum crystallinum, Mesembryanthemum barklyi, Drosanthemum diversifolium, Delosperma echinatum, Trichodiadema bulbosum, Lampranthus bicolor, Ruschia diversifolia, Leipoldtia schultzei, Vanzijlia annulata and Carpobrotus acinaciformis) screened in this study were populated with endophytes on all occasions investigated. In total, 450 plant fragments were plated from which 253 mycelial fungal endophytes were isolated, yielding a colonization frequency of $56.2 \%$. These isolates comprised 
59 fungal species, from 25 genera (Table 1, Fig. 2). Fourteen of the isolated species (23.7\%) can be considered as rare species associated with Aizoaceae in the region - with sequences corresponding with genera with only a single representative in the sample (singletons). Alternaria alternata, Aspergillus parasiticus, Chaetosphaeronema hispidulum and Cladosporium cladosporioides were among the only six species isolated from samples of both the dry and flowering seasons. Seasonal specificity was observed; with 32 and 21 fungal endophytes isolated only from samples collected during the flowering season and dry season, respectively.

Table 1 List of fungal endophytes isolated from Aizoaceae from the Namaqua National Park in the Succulent Karoo biodiversity hotspot, South Africa, during the dry and flowering seasons.

\begin{tabular}{|c|c|c|c|c|c|c|}
\hline \multirow{2}{*}{ Endophytic fungi } & \multicolumn{6}{|c|}{ Season } \\
\hline & GenBank\# & PPRI\# & Dry & Flr & Tot & $\mathbf{R A}$ \\
\hline Alternaria alternata & $\underline{\text { AF347031 }}$ & 16010 & 11 & 13 & 24 & 9.486 \\
\hline Alternaria eureka & $\underline{\text { NR136016 }}$ & 17624 & 0 & 5 & 5 & 1.976 \\
\hline Alternaria palandui & $\underline{\text { DQ323682 }}$ & 16053 & 6 & 0 & 6 & 2.372 \\
\hline Alternaria pellucida & $\underline{\text { AF347031 }}$ & 14425 & 0 & 1 & 1 & 0.395 \\
\hline Alternaria sp. & $\underline{\text { AF347031 }}$ & 14422 & 7 & 2 & 9 & 3.557 \\
\hline Alternaria tenuissima & $\underline{\text { EF031053 }}$ & 14429 & 0 & 4 & 4 & 1.581 \\
\hline Alternaria yali-inficiens & $\underline{\mathrm{AF} 347031}$ & 16051 & 1 & 0 & 1 & 0.395 \\
\hline Aspergillus aureolus & $\underline{\text { KY808743 }}$ & 17735 & 0 & 6 & 6 & 2.372 \\
\hline Aspergillus fischeri & $\underline{\text { EF669936 }}$ & 17632 & 0 & 6 & 6 & 2.372 \\
\hline Aspergillus flavus & $\underline{\text { AF027863 }}$ & 14424 & 0 & 2 & 2 & 0.791 \\
\hline Aspergillus fumigatiaffinis & $\underline{\text { EF669936 }}$ & 13089 & 0 & 2 & 2 & 0.791 \\
\hline Aspergillus neoniveus & $\underline{\text { NR137474 }}$ & 13094 & 0 & 2 & 2 & 0.791 \\
\hline Aspergillus parasiticus & $\underline{\mathrm{JN} 942865}$ & 14430 & 3 & 4 & 7 & 2.767 \\
\hline Aspergillus ustus & $\underline{\text { EF652455 }}$ & 17765 & 0 & 2 & 2 & 0.791 \\
\hline
\end{tabular}


Endophytic fungi

\begin{tabular}{|c|c|c|c|c|c|c|}
\hline Boeremia exigua & $\underline{\text { KR653200 }}$ & 16016 & 2 & 0 & 2 & 0.791 \\
\hline Chaetomium carinthiacum & $\underline{\text { KT214565 }}$ & 17666 & 0 & 1 & 1 & 0.395 \\
\hline Chaetomium funicola & $\underline{\text { GU563369 }}$ & 17640 & 0 & 2 & 2 & 0.791 \\
\hline Chaetosphaeronema hispidulum & $\underline{\text { KF251148 }}$ & 17732 & 4 & 4 & 8 & 3.162 \\
\hline Cladosporium allicinum & $\underline{\text { EF679350 }}$ & 16052 & 5 & 0 & 5 & 1.976 \\
\hline Cladosporium cladosporioides & JN942904 & 15983 & 8 & 6 & 14 & 5.534 \\
\hline Cladosporium licheniphilum & HM148111 & 16014 & 1 & 0 & 1 & 0.395 \\
\hline Cladosporium oxysporum & HM148120 & 16032 & 1 & 0 & 1 & 0.395 \\
\hline Cladosporium phyllophilum & HM148154 & 16013 & 2 & 0 & 2 & 0.791 \\
\hline Cladosporium sp. & JN942904 & 15990 & 5 & 0 & 5 & 1.976 \\
\hline Cladosporium tenuissimum & $\underline{\text { HM148197 }}$ & 16038 & 2 & 0 & 2 & 0.791 \\
\hline Cladosporium uredinicola & $\underline{\text { AY362001 }}$ & 16046 & 1 & 0 & 1 & 0.395 \\
\hline Curvularia borreriae & $\underline{\text { HE861848 }}$ & 14431 & 0 & 3 & 3 & 1.186 \\
\hline Curvularia spicifera & $\underline{\text { KJ922377 }}$ & 13102 & 0 & 2 & 2 & 0.791 \\
\hline Curvularia trifolii & $\underline{\text { HG779023 }}$ & 13091 & 0 & 6 & 6 & 2.372 \\
\hline Epicoccum nigrum & $\underline{\text { FJ426996 }}$ & 16007 & 5 & 0 & 5 & 1.976 \\
\hline Fusarium chlamydosporum & GQ505439 & 17664 & 0 & 4 & 4 & 1.581 \\
\hline Fusarium oxysporum & $\underline{\mathrm{U} 34566}$ & 17777 & 0 & 24 & 24 & 9.486 \\
\hline Fusarium solani & $\underline{\mathrm{AF} 178409}$ & 17659 & 0 & 1 & 1 & 0.395 \\
\hline Neophaeosphaeria sp. & NR1378331 & 16017 & 1 & 0 & 1 & 0.395 \\
\hline Paecilomyces victoriae & JN899393 & 17711 & 0 & 8 & 8 & 3.162 \\
\hline Penicillium abidjanum & GU981618 & 17635 & 0 & 1 & 1 & 0.395 \\
\hline Penicillium atrosanguineum & GU944599 & 17702 & 0 & 2 & 2 & 0.791 \\
\hline Penicillium canescens & AF033493 & 17642 & 0 & 1 & 1 & 0.395 \\
\hline
\end{tabular}

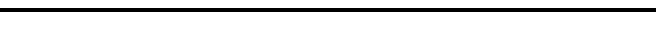

GenBank\# PPRI\# Dry Flr Tot RA

Season 


\section{Endophytic fungi}

\begin{tabular}{|c|c|c|c|c|c|c|}
\hline \multirow{2}{*}{ Endophytic fungi } & \\
\hline & GenBank\# & PPRI\# & Dry & Flr & Tot & $\mathbf{R A}$ \\
\hline Penicillium chrysogenum & $\underline{\mathrm{AF} 033465}$ & 13087 & 0 & 3 & 3 & 1.186 \\
\hline Penicillium corylophilum & $\underline{\mathrm{AF} 033450}$ & 15997 & 3 & 0 & 3 & 1.186 \\
\hline Penicillium rubefaciens & $\underline{\mathrm{KC} 411677}$ & 15986 & 3 & 0 & 3 & 1.186 \\
\hline Penicillium vanluykii & $\underline{\mathrm{JX} 997007}$ & 13099 & 0 & 2 & 2 & 0.791 \\
\hline Periconia macrospinosa & $\underline{\text { KP183999 }}$ & 17627 & 0 & 1 & 1 & 0.395 \\
\hline Phoma herbarum & $\underline{\mathrm{JF810530}}$ & 16006 & 2 & 0 & 2 & 0.791 \\
\hline Phoma sp. & $\underline{\text { KT389535 }}$ & 13095 & 6 & 4 & 10 & 3.953 \\
\hline Phyllosticta capitalensis & $\underline{\mathrm{JF} 261459}$ & 14433 & 0 & 3 & 3 & 1.186 \\
\hline Pleosporales sp. & & 16048 & 8 & 0 & 8 & 3.162 \\
\hline Preussia terricola & $\underline{\text { GQ203765 }}$ & 17623 & 0 & 1 & 1 & 0.395 \\
\hline Pseudodiplodia ruticola & $\underline{\text { GQ203765 }}$ & 16003 & 2 & 0 & 2 & 0.791 \\
\hline Pseudopithomyces chartarum & $\underline{\text { DQ384571 }}$ & 16033 & 2 & 0 & 2 & 0.791 \\
\hline Purpureocillium lilacinum & $\underline{\text { FR734101 }}$ & 13104 & 0 & 4 & 4 & 1.581 \\
\hline Rhizopus arrhizus & $\underline{\text { AF543522 }}$ & 13092 & 0 & 2 & 2 & 0.791 \\
\hline Schizothecium curvisporum & $\underline{\text { AY999119 }}$ & 17628 & 0 & 1 & 1 & 0.395 \\
\hline Talaromyces amestolkiae & $\underline{\mathrm{JX} 315678}$ & 16043 & 6 & 0 & 6 & 2.372 \\
\hline Talaromyces pinophilus & $\underline{\mathrm{JN} 899382}$ & 17634 & 0 & 10 & 10 & 3.953 \\
\hline Talaromyces purpureogenus & $\underline{\mathrm{JX} 315671}$ & 16009 & 3 & 0 & 3 & 1.186 \\
\hline Trichoderma ghanese & $\underline{\mathbf{Z 3 1 0 1 5}}$ & 13101 & 0 & 2 & 2 & 0.791 \\
\hline Trichoderma spirale & $\underline{\mathrm{AF} 400262}$ & 17661 & 0 & 5 & 5 & 1.976 \\
\hline Truncatella spadicea & $\underline{\text { DQ278989 }}$ & 16027 & 1 & 0 & 1 & 0.395 \\
\hline Total & & & 101 & 152 & 253 & 100.00 \\
\hline
\end{tabular}

\section{Season}

* Abbreviations: GenBank\# Closest match to GenBank accession, PPRI\# Accession number in the South African National Collection of Fungi, Dry Number of dry season isolates, Flr Number of flowering season isolates, Tot Total number of isolates, $R A$ Relative abundance of each fungal endophyte species 


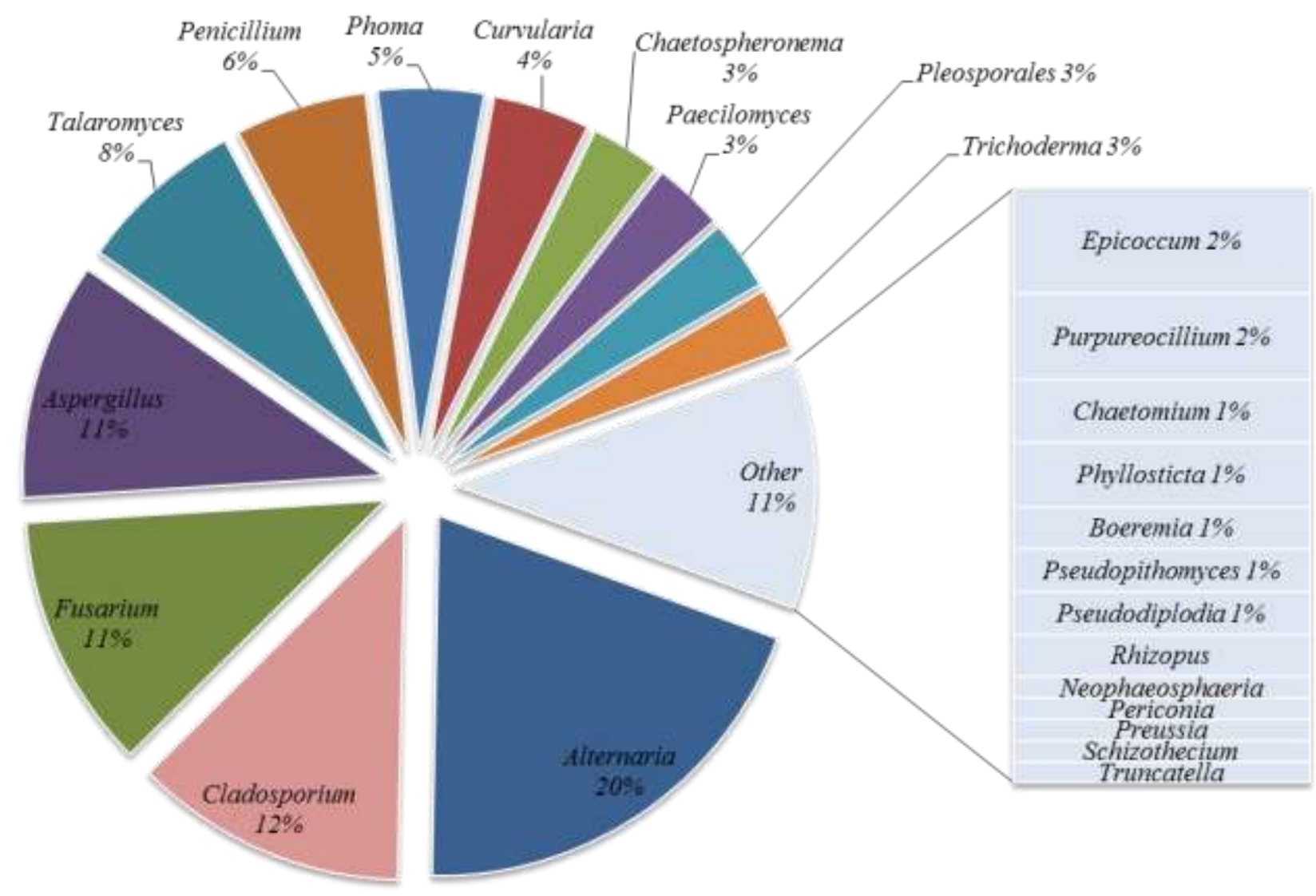

Fig. 2. Relative abundance of fungal genera isolated from Aizoaceae from the Namaqua National Park in the Succulent Karoo biodiversity hotspot, South Africa, during the dry and flowering seasons combined (total population).

Non-metric multidimensional scaling (NMDS) clearly separated samples from the two seasons (Fig. 3), illustrating highly significant seasonality in the culturable fungal endophyte communities. The different samples taken during the flowering season were more similar to each other than the different samples taken during the dry season, as was evident from the closer clustering of the former samples. ANOSIM was used to visualise differences in relative abundance of the fungal endophyte communities associated with seasonality (Fig. 4a) and presence / absence data (Fig. 4b). It is clear that differences between the dry and flowering season were significantly higher, compared to differences within each season, as evident from the higher ranked distances. 

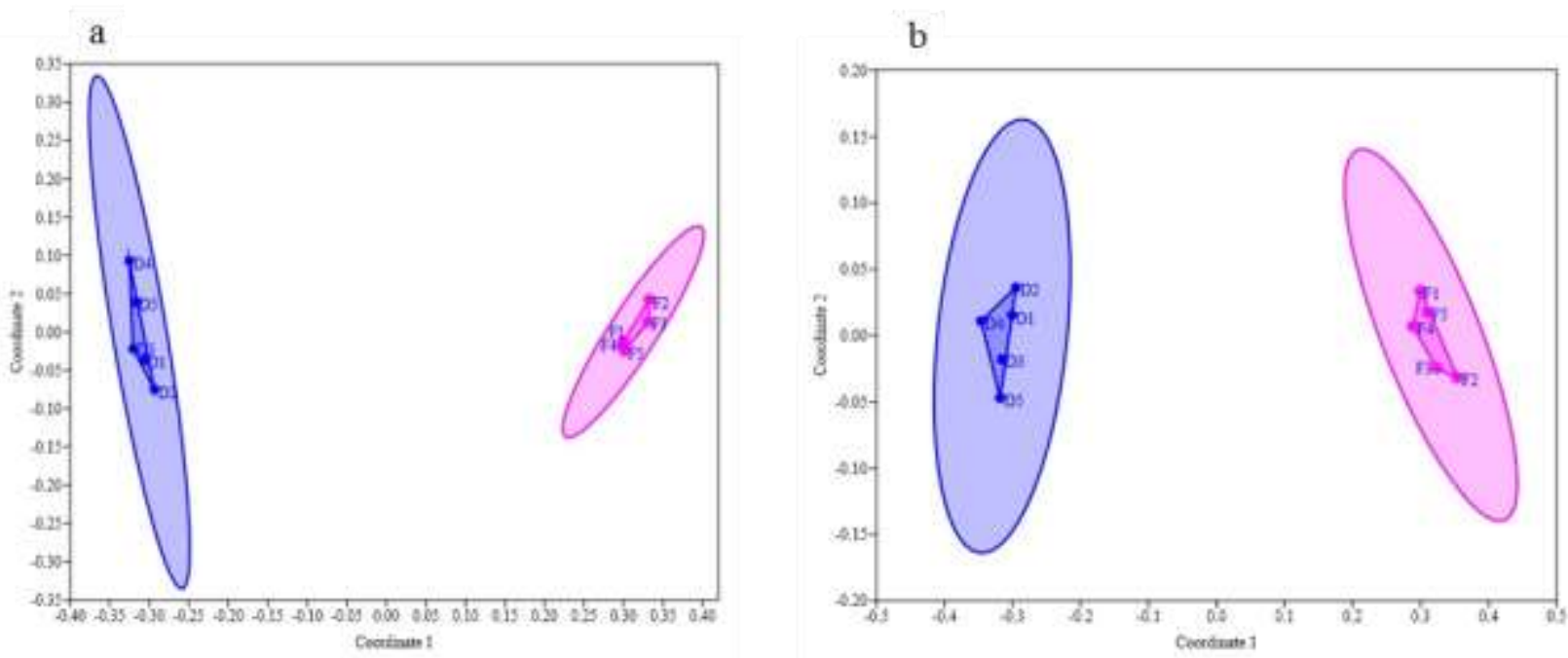

Fig. 3. Non-metric multidimensional scaling (NMDS) plots showing relationships between the fungal endophyte communities isolated from Aizoaceae sampled from the Namaqua National Park, during different sampling seasons $(\mathrm{D}=$ Dry season; $\mathrm{F}=$ Flowering season $)$ using a) relative abundance as an indicator with the Bray-Curtis dissimilarity index and b) presence / absence data as an indicator with the Jaccard dissimilarity index. Convex hulls and 95\% confidence ellipses are shown. (stress $=0.1689$ and 0.127 , respectively).
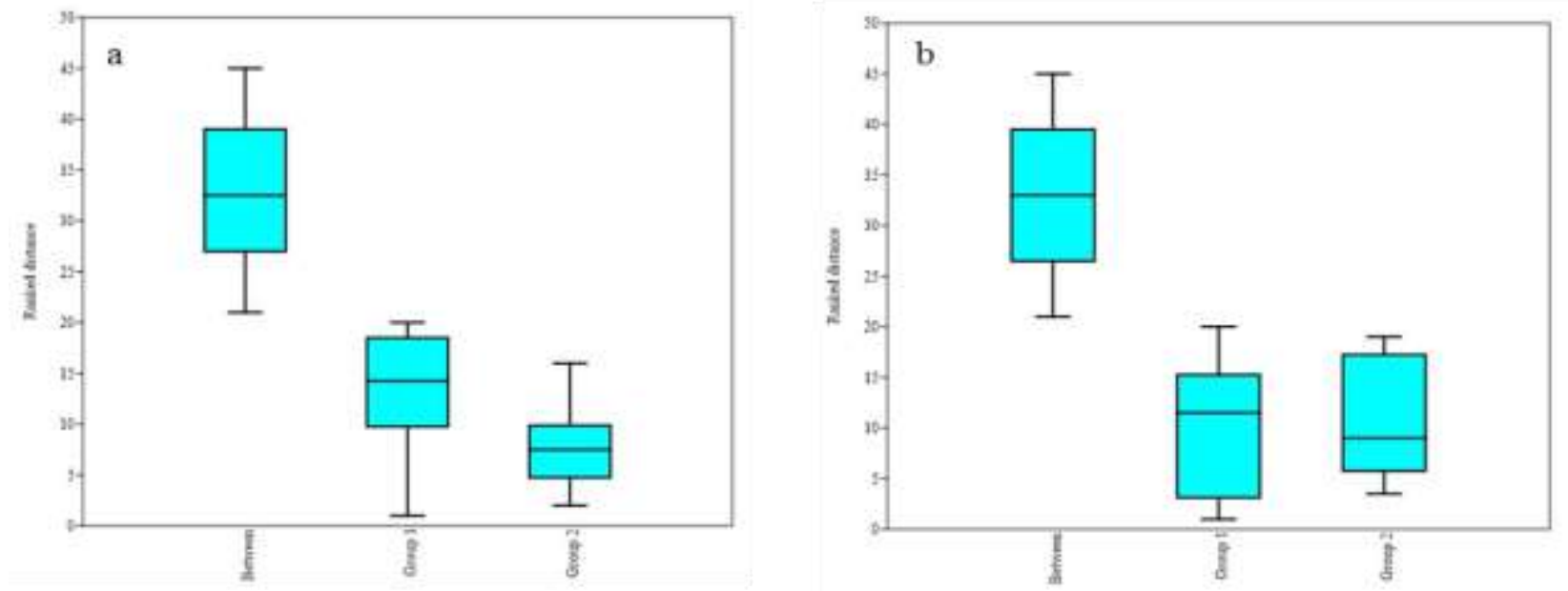

Fig. 4. One way analysis of similarity (ANOSIM) of fungal endophytes from Aizoaceae from the Namaqua National Park, comparing distances between and within fungal communities sampled during different seasons using the (a) Bray-Curtis dissimilarity index ( $\mathrm{R}=1, \mathrm{p}<0.0073$ ) and (b) Jaccard dissimilarity index $(\mathrm{R}=1, \mathrm{p}<0.0083)$ with 9999 permutations performed. Group $1=$ Dry samples; Group 2 = Flowering samples. 
The genus Fusarium (29 isolates) was the most abundant isolate from samples from the flowering season followed by Alternaria (25 isolates) and Aspergillus (24 isolates). In the dry season Alternaria and Cladosporium (25 isolates each) were most abundant followed by Talaromyces (9 isolates) (Table 1). The total fungal population was dominated by four genera: Alternaria (20\%), Cladosporium (12\%), Fusarium (11\%) and Aspergillus (11\%) (Fig. 2). The remaining $46 \%$ of fungi were represented in 21 genera. Genera rarely isolated included Neophaeosphaeria, Periconia, Preussia, Schizothecium and Truncatella (Fig. 2). SIMPER analysis (data not shown) confirmed that Fusarium oxysporum, Paecilomyces victoriae and Talaromyces pinophilus were the largest contributors to the differences in community structure observed for fungal endophytes from the different seasons.

Rarefaction curves did not show saturation, indicating that fungal endophyte diversity was underestimated and more sampling is advised (Fig. 5). Diversity indices (Table 2) indicate that a diverse community of endophytic fungi can be cultured from Aizoaceae plants. The diversity observed was higher during the flowering season compared to the dry season.

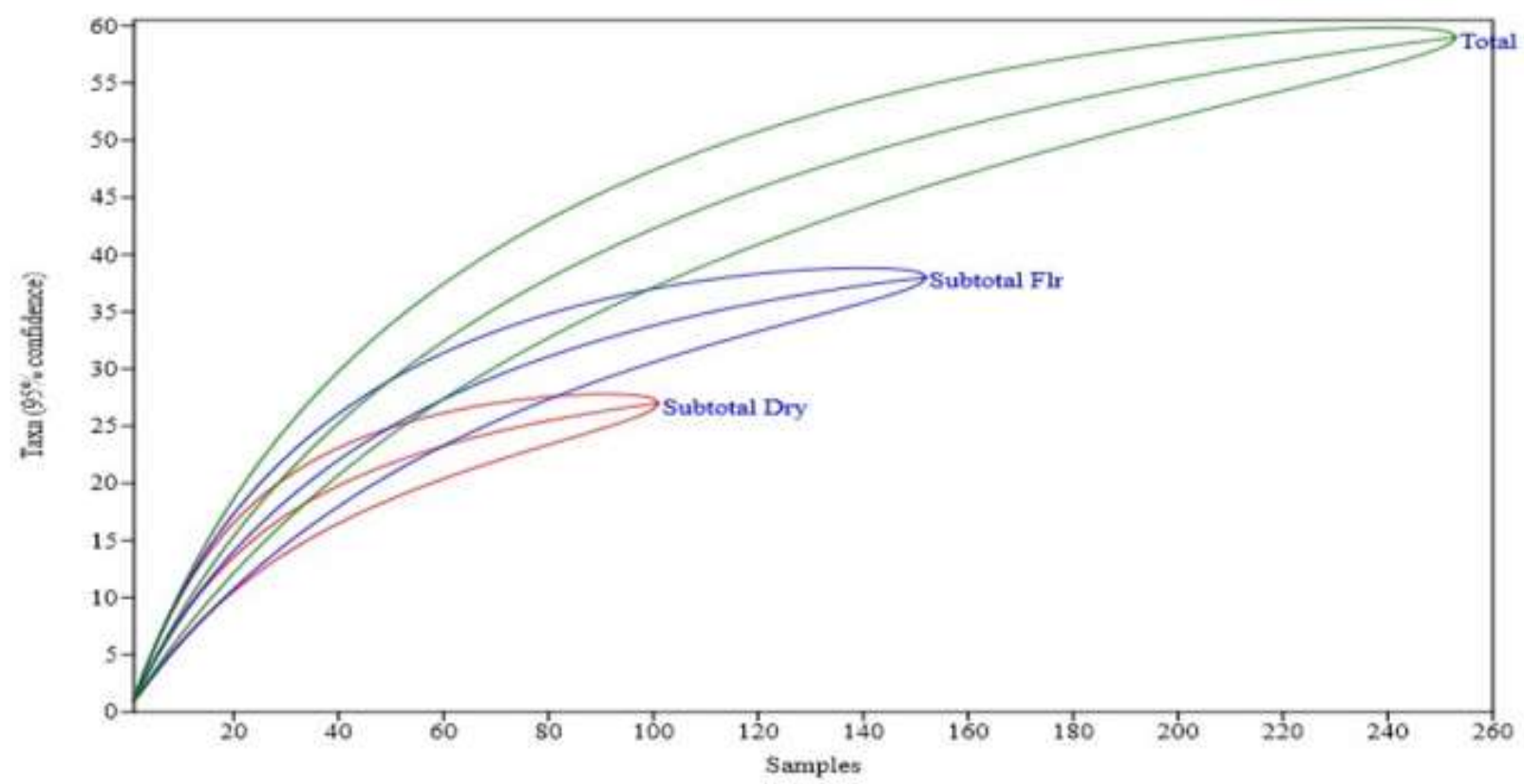

Fig. 5. Species accumulation curve of the fungal endophyte communities isolated from Aizoaceae in the Namaqua National Park, during the flowering (Subtotal Flr) season, dry (Subtotal Dry) season and both seasons combined (Total). 
Table 2 Diversity indices of fungal endophytes isolated from Aizoaceae plants from the Namaqua National Park in the Succulent Karoo biodiversity hotspot, South Africa.

\begin{tabular}{llll}
\hline Indices & \multicolumn{2}{c}{ Season } & Total \\
\hline Richness of species & Dry & Flowering & \\
Number of isolates & 27 & 38 & 59 \\
Margalef's (richness) & 101 & 152 & 253 \\
Fisher's $\boldsymbol{\alpha}$ (diversity) & 5.63 & 7.37 & 10.48 \\
Shannon's (H') (entropy) & 12.07 & 16.26 & 24.19 \\
Simpson's (evenness) & 3.06 & 3.27 & 3.55 \\
Berger-Parker (dominance) & 0.94 & 0.94 & 0.96 \\
\hline
\end{tabular}

\section{Discussion}

Among the more exciting ecological discoveries of the past century is the realisation that all macro organisms are hosts to microorganisms. The significance of the diverse communities and indispensable functions performed by fungal endophytes has only recently been recognised, but with limited research focussing on plants inhabiting dry environments (Murali et al., 2007; Bezerra et al., 2012, 2013; Loro et al., 2012). Low moisture ecosystems characterise almost 40\% of land surface on Earth, with studies on global climate change predicting a continued increase in the percentage of arid land, highlighting the importance of arid region research and conservation (Collins et al., 2008; Young et al., 2016).

Estimation of fungal endophyte diversity is biased by many parameters including sampling strategy, method of isolation, initial incubation temperature, ability to grow in culture and technique of identification (Higgins et al., 2011; Suryanarayanan et al., 2011). Certain fungal groups like endophytic basidiomycetes (as was the case in this study) fail to be detected by culturing approaches alone (Suryanarayanan et al., 2011, Singh et al., 2017). Therefore it has recently become more commonplace to investigate the total fungal endophyte community from different environments, using a combination of culturing and culture-independent approaches, 
such as next generation sequencing (NGS) (Hibbett et al., 2011; Singh et al., 2017). The culturing approach was used in this study firstly to enable depositing of fungal endophytes from Aizoaceae from this unique environment in the South African National Collection of Fungi living fungal collection (PPRI). Secondly, to highlight the significance of the area and contribute to the understanding of its importance with a view of creating a platform for future studies that will no doubt need to include NGS approaches.

In this study, the endophytic fungal community associated with Aizoaceae in the Namaqua National Park in the Succulent Karoo biodiversity hotspot was observed to be highly diverse. The fungal endophyte community associated with Aizoaceae shows some similarities with those of the closely related family Cactaceae, with respect to species richness and colonization frequency. Bezerra et al. (2012) isolated 44 fungal endophytes from Opuntia ficus-indica, or "prickly pear", grown in the semi-arid regions of Brazil. A similar number of endophytic fungi were isolated from forage cacti in Brazil (Bezerra et al., 2013), while 23 and 22 fungal endophytes have been isolated from cacti in Australia and Arizona (USA), respectively (Fisher et al., 1994; Suryanarayanan et al., 2005). Most of these fungal endophytes belonged to the phylum Ascomycota, as is the case in the current study.

In our study Alternaria was the most frequently isolated genus: this genus has previously been reported as the most frequently observed in many arid regions (such as Arizona, Mexico and Australia) as well as in different plant species, including cacti (such as Myrtillocactus geometrizans and Opuntia spp.) and Agave (Suryanarayanan et al., 2005; Bezerra et al., 2012; Fonseca-García et al., 2016). As for our study with Aizoaceae, Alternaria was found to be nonhost specific in Cactaceae - a plant family also associated with dry environments (Bezerra et al., 2013; Fonseca-García et al., 2016). In this study, different species of Alternaria were isolated during different seasons, but the genus Alternaria did not contribute significantly to seasonality. The absence of seasonality was also observed by Yadav et al. (2016) in their study on endophytic fungi associated with Eugenia jambolana Lam. 
The percentage of rarely isolated species identified from Aizoaceae in the Succulent Karoo biome (36.4\%) was almost $10 \%$ higher than the figure reported by Loro et al. (2012) for the endophyte community associated with plants commonly found in semi-arid Northwest Venezuela (27\%). The percentage of rarely isolated fungal endophyte species in this study was lower than found (58\%: Bezerra et al., 2013) in a study on Cereus jamacaru. However, these authors included $30 \%$ sterile mycelia in their count of rare species and only used morphological characteristics to determine species identity. Both the studies of Loro et al. (2012) and Bezerra et al. (2013) were also based on once-off sampling. In the current study three fungal genera; Periconia, Preussia and Schizothecium were isolated only from flowering season samples while Neophaeosphaeria and Truncatella were isolated only from the dry season samples. Results of once-off sampling studies are therefore highly unlikely to yield a complete picture of the culturable diversity of rare fungal endophytes present in arid regions. Interestingly, only a single species from genus Preussia was isolated from Aizoaceae in the Succulent Karoo biodiversity hotspot although this genus was the most frequently isolated fungal endophyte in a study of fungal endophytes from the Sonoran Desert (Massimo et al., 2015).

Results from this study were in stark contrast with those reported by Suryanarayanan et al. (2005) from their study of endophytic fungi associated with cacti in Arizona, where they reported low diversity in endophyte assemblages of arid zone plants due to water and nutrient limitation. Endophytic fungi isolated from cacti from Arizona were found to have a maximum Fisher's alpha value of 2.1 (Suryanarayanan et al., 2005), which was significantly less than the lowest value of 12.07 calculated for dry season sampling of Aizoaceae from the Succulent Karoo. Results of the current study correlated better with fungal endophyte diversity in the cactus $C$. jamacaru, where culturable diversity was determined to have a Fisher's alpha value of 19.32 and a Margalef index of 9.722 (Bezerra et al., 2013). These authors also relied only on morphological identification for their conclusion that endofungal diversity was high in $C$. jamacaru. We suggest that morphological identification methods may over-estimate species diversity and therefore result in 
higher diversity index values. Loro et al. (2012) estimated endofungal diversity, using Fisher's alpha values, as 25.06 for semi-arid Northwest Venezuela, only slightly higher than the 24.19 calculated for the total community in the Succulent Karoo. The high endofungal diversity associated with Aizoaceae in the Succulent Karoo may result, in part, to the presence of microenvironmental niches, known to have an effect in other arid regions (Porras-Alfaro et al., 2008).

Pawlowska et al. (2014) presented the concept that environmental factors associated with different seasons may influence species diversity. In the current study, seasonal specificity was clearly observed, with higher endofungal diversity estimates in the flowering season than in the dry season. In their study of seasonal influences on Indian endophytic mycobiota, Yadav et al. (2016) found species of genera Aspergillus and Chaetomium only present during the rainy season. Seasonal specificity was also observed for the genus Phyllosticta (Suryanarayanan et al., 2005). Similarly, species of Aspergillus, Chaetomium and Phyllosticta isolated during this study showed seasonal specificity. These genera were only isolated after the highest rainfall period in the Namaqua National Park, during the flowering season, with the exception of Aspergillus parasiticus that was also present as an endophyte in the dry season.

Fusarium oxysporum, Talaromyces pinophilus and Paecilomyces victoriae were the greatest contributors to the seasonal differences observed in the fungal endophyte communities associated with Aizoaceae in this study. All three these species were absent in dry season samples, but 24, 10 and 8 isolates, respectively, were isolated from flowering season samples. A possible explanation for such differences is that fungal genera only isolated during the flowering (wet) season may require higher temperatures and humidity for growth. For example, Fusarium populations are known to increase after periods of rainfall (Bateman and Murray, 2001). Different selection pressures, as observed during the different seasons in this study, are known to play a role in endophyte species composition (Yadav et al., 2016). Seasonality observed in fungal endophyte communities can result from the relationships these fungi have with plants during increased plant productivity in the environment (Giauque and Hawkes, 2016). Some endophytes 
have the ability to establish themselves in the plant under active plant growth conditions, while the growth of other endophytes declines with an increase in plant metabolic activity (Martins et al., 2016).

Arid region plants may even be dependent on endofungal associations for production of secondary metabolites such as enzymes that increase plant fitness (Loro et al., 2012). The diversity of secondary metabolites produced by fungal endophytes, including those produced by endophytes from arid regions, has recently been comprehensively reviewed (Aly et al., 2010, 2011). Several of these secondary metabolite-producing fungal genera were isolated as endophytes associated with Aizoaceae in this study, including Alternaria, Aspergillus, Curvularia, Fusarium, Penicillium, Phyllosticta and Periconia (one of the rarely isolated species identified in this study). Redman et al. (2001) hypothesized that extreme environments may alter production of fungal secondary metabolites, favouring the conversion from a free-living or pathogenic to a mutualistic lifestyle. It is therefore possible that some fungal species, such as Fusarium oxysporum, typically known to be pathogenic, may in preference exhibit an endophytic lifestyle in a stressful environment (Leslie and Summerell, 2006) such as the arid environment of the Succulent Karoo biodiversity hotspot investigated in this study. Fusarium oxysporum has been isolated as an endophyte from succulent Cactaceae plants (Bezerra et al., 2013) and was isolated as an endophyte from Aizoaceae in this study.

In conclusion, we have observed that seasonality plays a critical role in determining the culturable fungal endophyte communities associated with Aizoaceae in the Namaqua National Park in the Succulent Karoo biodiversity hotspot, South Africa. Our results agree with the recent findings of Bezerra et al. (2013) and Massimo et al. (2015) that fungal endophytes from arid environments are highly diverse and include species rarely isolated elsewhere. In addition, the results of this study highlight the importance of considering seasonality, including the influence of temperature, rainfall and plant growth stage, in fungal diversity studies. We argue that once-off fungal diversity studies cannot in any way represent of the dynamics in fungal populations. 
Symbiotic relationships can have a direct or indirect impact on the structure, function and composition of plant communities (Loro et al., 2012; Rudgers et al. 2015). Fungal endophytes (e.g. Curvularia and Fusarium) known to improve stress tolerance in plants from arid environments (Redman et al., 2001; Bezerra et al., 2013) have been isolated. Some fungal endophytes (e.g. Penicillium, Phyllosticta and Periconia) have also been shown to have the ability to transfer the 'plant fitness' benefits they bestow on native plants to plants of agricultural and horticultural importance (Aly et al., 2010, 2011). Although research efforts in arid regions remain challenging, it can be justified by the countless insights that can be gained in informing global biodiversity studies (Loro et al., 2012; Bezerra et al., 2013). The value of researching and protecting the fungal biodiversity of the Succulent Karoo and documenting native fungi has been highlighted by the recent efforts to exploit the area for its shale gas. Improving human well-being by protecting biological richness and adopting green economies is increasingly becoming important in South Africa, as is the case worldwide. Further research into endophytes that improve plant fitness and health of Aizoaceae in the Succulent Karoo and how these endophytes can be protected and sustainably used is needed.

\section{Declarations of interest: none}

Contributions of authors: Zelda Pieterse: Laboratory work and writing the manuscript; Theresa Aveling: Field work and writing the manuscript; Adriaana Jacobs: data analysis and writing the manuscript; Don Cowan: writing the manuscript and securing funding.

\section{Acknowledgements}

The authors would like to thank Edgar Mangwende for his assistance in sampling. We thank South African National Parks for granting us a permit to conduct research in the Namaqua 
National Park. The authors are grateful for funding received from the Genomics Research Institute of the University of Pretoria and from the National Research Foundation.

\section{References}

Aly, A. H., Debbab, A., Kjer, J., and Proksch, P. (2010). Fungal endophytes from higher plants: a prolific source of phytochemicals and other bioactive natural products. Fungal Diversity, 41(1), 1-16.

Aly, A. H., Debbab, A., and Proksch, P. (2011). Fungal endophytes: unique plant inhabitants with great promises. Applied Microbiology and Biotechnology, 90(6), 1829-1845.

Bateman, G. L., and Murray, G. (2001). Seasonal variations in populations of Fusarium species in wheat-field soil. Applied Soil Ecology, 18(2), 117-128.

Bezerra, J. D. P., Santos, M. G. S., Svedese, V. M., Lima, D. M. M., Fernandes, M. J. S., Paiva, L. M. and Souza-Motta, C. M. (2012). Richness of endophytic fungi isolated from Opuntia ficus-indica Mill. (Cactaceae) and preliminary screening for enzyme production. World Journal of Microbiology and Biotechnology, 28(5), 1989-1995.

Bezerra, J. D. P., Santos, M. G. S., Barbosa, R. N., Svedese, V. M., Lima, D. M. M., Fernandes, M. J. S., Gomes, B. S., Paiva, L. M., Almeida-Cortez, J. S., and Souza-Motta, C.M. (2013). Fungal endophytes from cactus Cereus jamacaru in Brazilian tropical dry forest: A first study. Symbiosis, 60, 53-63.

Bonfim, J. A., Vasconcellos, R. L. F., Baldesin, L. F., Sieber, T. N., and Cardoso, E. J. B. N. (2016). Dark septate endophytic fungi of native plants along an altitudinal gradient in the Brazilian Atlantic forest. Fungal Ecology, 20, 202-210.

Crous, P. W., Gams, W., Stalpers, J. A., Robert, V., and Stegehuis, G. (2004). MycoBank: an online initiative to launch mycology into the 21st century. Studies in Mycology, 50(1), 19-22. 
Desmet, P., and Cowling, R. (2004). Using the species-area relationship to set baseline targets for conservation. Ecology and Society, 9(2), 11.

Fonseca-García, C., Coleman-Derr, D., Garrido, E., Visel, A., Tringe, S. G., and PartidaMartínez, L. P. (2016). The cacti microbiome: Interplay between habitat-filtering and hostspecificity. Frontiers in Microbiology, 7, 150.

GenBank. (2016). NCBI’s GenBank sequence database: http://www.ncbi.nlm.nih.gov.

Giauque, H., and Hawkes, C. V. (2016). Historical and current climate drive spatial and temporal patterns in fungal endophyte diversity. Fungal Ecology, 20, 108-114.

Google maps. (2017). Namaqua National Park. Retrieved from: https://www.google.ca/maps/place/30\%C2\%B009'19.0\%22S+17\%C2\%B043'55.0\%22E/@_ $\underline{30.1552778,17.7297557,17 \mathrm{z} / \mathrm{data}=! 3 \mathrm{~m} 1 ! 4 \mathrm{~b} 1 ! 4 \mathrm{~m} 5 ! 3 \mathrm{~m} 4 ! 1 \mathrm{~s} 0 \mathrm{x} 0: 0 \mathrm{x} 0 ! 8 \mathrm{~m} 2 ! 3 \mathrm{~d}-}$ 30.1552778!4d17.7319444?hl=en.

Hammer, Ø., Harper, D. A. T., and Ryan, P. D. (2001). PAST- paleontological statistics software package for education and data analysis. Palaeontologia Electronica, 4, 1-9.

Hibbett, D. S., Ohman, A., Glotzer, D., Nuhn, M., Kirk, P., and Nilsson, R. H. (2011). Progress in molecular and morphological taxon discovery in fungi and options for formal classification of environmental sequences. Fungal Biology Reviews, 25(1), 38-47.

Higgins, K. L., Coley, P. D., Kursar, T. A., and Arnold, A. E. (2011). Culturing and direct PCR suggest prevalent host generalism among diverse fungal endophytes of tropical forest grasses. Mycologia, 103(2), 247-260.

Klak, C., Reeves, G., and Hedderson, T. (2004). Unmatched tempo of evolution in Southern African semi-desert ice plants. Nature, 427(6969), 63-65.

Leslie, J. F., and Summerell, B. A. (2006). The Fusarium laboratory manual. Blackwell Publishing Ltd., Oxford, UK. 
Loro, M., Valero-Jiménez, C. A., Nozawa, S., and Márquez, L.M. (2012). Diversity and composition of fungal endophytes in semi-arid Northwest Venezuela. Journal of Arid Environments, 85, 46-55.

Martins, F., Pereira, J. A., Bota, P., Bento, A., and Baptista, P. (2016). Fungal endophyte communities in above-and belowground olive tree organs and the effect of season and geographic location on their structures. Fungal Ecology, 20, 193-201.

Massimo, N. C., Nandi Devan, M. M., Arendt, K. R., Wilch, M. H., Riddle, J. M., Furr, S. H., and Arnold, A. E. (2015). Fungal endophytes in aboveground tissues of desert plants: Infrequent in culture, but highly diverse and distinctive symbionts. Microbial Ecology, 70(1), $61-76$.

Mishra, V. K., Singh, G., Passari, A. K., Yadav, M. K., Gupta, V. K., and Singh, B. P. (2016). Distribution and antimicrobial potential of endophytic fungi associated with ethnomedicinal plant Melastoma malabathricum L. Journal of Environmental Biology, 37(2), 229.

Moncrieff, G. R., Scheiter, S., Slingsby, J. A., and Higgins, S. I. (2015). Understanding global change impacts on South African biomes using dynamic vegetation models. South African Journal of Botany, 101, 16-23.

Murali, T. S., Suryanarayanan, T. S., and Venkatesan, G. (2007). Fungal endophyte communities in two tropical forests of southern India: diversity and host affiliation. Mycological Progress, 6(3), 191-199.

Myers, N., Mittermeier, R. A., Mittermeier, C. G., Da Fonseca, G. A., and Kent, J. (2000). Biodiversity hotspots for conservation priorities. Nature, 403(6772), 853-858.

Redman, R. S., Dunigan, D. D., and Rodriguez, R. J. (2001). Fungal symbiosis from mutualism to parasitism: Who controls the outcome, host or invader? New Phytologist, 151(3), 705-716.

Rodriguez, R. J., White Jr, J. F., Arnold, A. E., and Redman, R. S. (2009). Fungal endophytes: Diversity and functional roles. New Phytologist, 182(2), 314-330. 
SANParks (South African National Parks). (2014). Annual report 2013/2014. www.sanparks.co.za/assets/docs/general/annual-report-2014.pdf. Accessed 01-05-2015.

Singh, D. K., Sharma, V. K., Kumar, J., Mishra, A., Verma, S. K., Sieber, T. N., and Kharwar, R. N. (2017). Diversity of endophytic mycobiota of tropical tree Tectona grandis Linn. f.: Spatiotemporal and tissue type effects. Scientific Reports, 7(1), 3745.

Sloan, S., Jenkins, C. N., Joppa, L. N., Gaveau, D. L., and Laurance, W. F. (2014). Remaining natural vegetation in the global biodiversity hotspots. Biological Conservation, 177, 12-24.

Smith, G. F., Chesselet, P., Van Jaarsveld, E. J., Hartmann, H., Hammer, S., Van Wyk, B., and Kurzweil, H. (1998). Mesembs of the World. Briza Publications, Pretoria.

Suryanarayanan, T. S., Wittlinger, S. K., and Faeth, S. H. (2005). Endophytic fungi associated with cacti in Arizona. Mycological Research, 109(05), 635-639.

Suryanarayanan, T. S., Murali, T. S., Thirunavukkarasu, N., Rajulu, M. G., Venkatesan, G., and Sukumar, R. (2011). Endophytic fungal communities in woody perennials of three tropical forest types of the Western Ghats, southern India. Biodiversity and Conservation, 20(5), 913928.

White, T. J., Bruns, T., Lee, S. J. W. T., and Taylor, J. W. (1990). Amplification and direct sequencing of fungal ribosomal RNA genes for phylogenetics. PCR protocols: A guide to methods and applications eds. Innis, M. A., D. H. Gelfand, J. J. Sninsky, and T. J. White. (Academic Press, Inc., New York), 18, 315-322.

Yadav, M., Yadav, A., Kumar, S., and Yadav, J. P. (2016). Spatial and seasonal influences on culturable endophytic mycobiota associated with different tissues of Eugenia jambolana Lam. and their antibacterial activity against MDR strains. BMC Microbiology, 16(1), 44.

Young, A. J., Guo, D., Desmet, P. G., and Midgley, G. F. (2016). Biodiversity and climate change: Risks to dwarf succulents in Southern Africa. Journal of Arid Environments, 129, $16-24$. 